\title{
SIMPLICIDADE ALEGRE DE UM BIBLIÓFILO
}

Claudio Giordano

Para a grande maioria dos leitores brasileiros, Rubens Borba de Moraes é desconhecido, em que pese haver formado e legado à posteridade a notabilíssima Coleção Brasiliana e haver composto a melhor bibliografia sobre essa matéria; sem mencionar outros trabalhos de igual natureza e importância e sua competente ação na área de biblioteconomia. Não bastasse isso, não alcançou ainda maior público leitor apesar deste delicioso O Bibliófilo Aprendiz (agora em sua quinta edição pela BBMBiblioteca Brasiliana Mindlin), que sozinho deveria ter-lhe popularizado o nome. Diz ele no "Prefácio" que o escreveu "para passar o tempo, para prosear sobre um assunto por que me apaixonei". E recomenda "não perca tempo em ler esta prosa fiada de um velho bibliófilo", "quem não gosta de conversar sobre livros raros, quem não dá a menor importância a uma primeira edição, quem não pretende colecionar”.

Se não exatamente o contrário, recomendo encarecidamente que além dos aficionados ao livro, não percam a oportunidade de percorrer essas páginas sobretudo aqueles para os quais o livro não passa de objeto de leitura esporádica. Pois, o que se tem nele não é a apologia do livro feita por um colecionador obcecado, querendo provar 
Q

L

K

o

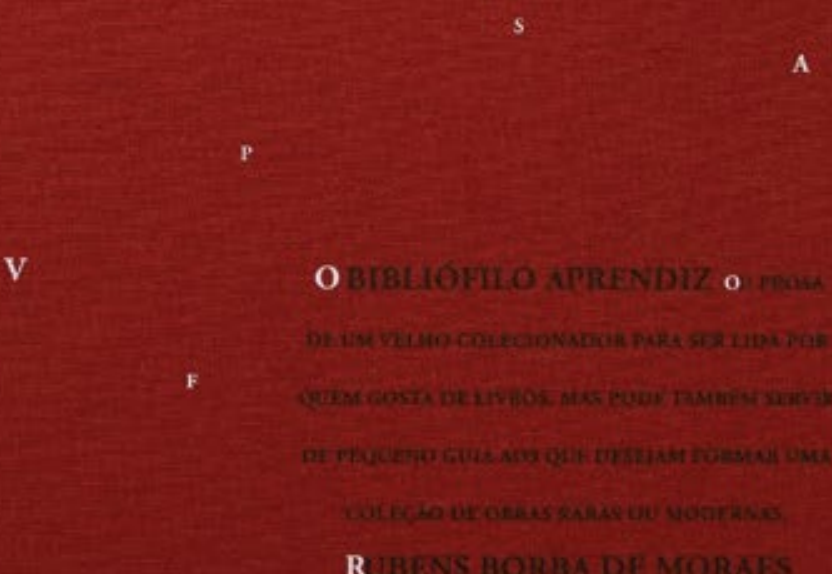

B

c

\footnotetext{
O Bibliófilo Aprendiz, de Rubens Borba de Moraes, publicado em 2018 pelo selo editorial Publicações Bвм.
} 
que escolheu o melhor lazer do mundo e buscando por isso aliciar novos colecionadores e futuros bibliófilos. Nem pensar! Em linguagem despojada, bem humorada, discorre o autor sobre a arte de colecionar como uma opção, entre muitas, de lazer divertido e apaixonante. Esconde a erudição, até porque - afirma - "em matéria de livros, tudo quanto sei só serve para mostrar o quanto ignoro”.

Lembra de saída que a bibliofilia, além de lazer, diletantismo, é obra de benemerência, o que não impede a frequente reação das esposas contra ela. Não se espere, porém, dele, "simples bibliófilo, conselhos de ordem familiar. Talvez o fato de muitos dos maiores colecionadores morrerem solteiros não seja sem significação”. Caso dele, aliás.

Para colecionar, impõe-se praticar a arte da compra e Borba discorre sobre o relacionamento com o livreiro, oportunidades, aspectos e estado dos livros, encadernações. A pretexto de pechinchas, lembra aos mais antigos a livraria do Gazeau, na Praça da Sé, em cujo "porão estavam os livros que ele [Gazeau] comprara há muito tempo" e onde "os amadores encontravam as edições esgotadas, as curiosidades e as raridades das quais Gazeau nem se lembrava da existência”. (Saudade! Na década de 1970, tive a ventura de encontrar no Gazeau - nem foi no porão - e comprar efetivamente por pechincha, os dezesseis volumes de uma edição pirata da tradução inglesa de As Mil e Uma Noites, de Richard F. Burton.)

Borba de Moraes não era regateador, sendo poucas as pechinchas entre os milhares de livros que adquiriu na vida. Com gosto conta como achou e comprou na França uma delas, o seu Brasil Pitoresco de Charles Ribeyrolles (Rio de Janeiro, 1859). Depois de longas e laboriosas negociações, foi afinal ao encontro de Monsieur Bernard, que se apressou em dizer "que tinha sido obrigado a tomar um táxi para transportar esse trambolho. Ficou mais contente quando lhe disse que eu pagaria o táxi. Para o exame do exemplar, convidei-o a ir a um outro bistrot, onde havia um vinho d'Arbois famoso. Examinei o Ribeyrolles. Era um exemplar perfeito, com todas as margens, como novo, numa encadernação ‘três-quartos' de marroquim vermelho da época. Nunca tinha visto um exemplar tão bonito. Paguei contente o preço combinado, paguei o táxi, paguei a comissão de Monsieur Bernard, paguei o vinho. Teria pago uma segunda garrafa, se o vinho d'Arbois não fosse tão traiçoeiro... Não me lembro, assim de momento, de ter feito muitas outras descobertas de livros raros por preço barato”. E acrescenta: "Nunca me arrependi de ter comprado um livro por um preço alto. Só me arrependo do que não comprei”.

Encadernações. "É um assunto delicado - diz ele - o de encadernação. Conselhos, neste caso, são como para mulher quando quer casar. 
Não adiantam. Só a experiência própria serve. Todo bibliófilo faz tolices, em matéria de encadernação. Esteja, pois, preparado a pagar o seu tributo e aprender à sua própria custa."

Alguns exemplares têm "verdadeira personalidade", escreve, ou então adquirem um "jeitão comum. Assim como os cachorros velhos se parecem com os donos, os livros de um colecionador têm um ar de família”. Referindo-se àqueles que fazem troca de ex-libris nos livros, diz: "Não é crime, não, mas não deixa de ser divertido essa maneira de se enganar a si próprio. Há também mulheres elegantes e ricas que usam joias falsas".

Depois de relacionar detalhadamente os cuidados a serem tomados no que tange à lavagem de livros no processo de restauro, conclui: "Banho não é recomendado para livros e gravuras, mas para os bibliófilos".

E continua destilando seu bom-humor a cada passo: "Não resta dúvida de que o pires com cal era um meio excelente para lutar contra a umidade, numa época em que o homem, para lutar contra o calor, só tinha o leque... Felizmente hoje existem uns aparelhos chamados condicionadores de ar”.

"É sempre mais garantido o próprio dono limpar, ele mesmo, sua biblioteca. É um divertimento, é uma ocasião que ele tem de folhear um livro que não pega há muito tempo, de verificar que um volume está precisando de um pequeno conserto... Livros exigem bom trato e carinho, como as mulheres”.

"Não vale a pena desanimar os bibliófilos inexperientes logo de início; já terão de sofrer bastante no correr da vida”.

Por ter aventado a hipótese de o paraíso terrestre estar situado no Brasil, o Padre Simão de Vasconcellos teve apreendida a sua obra Crônica da Companhia de Jesus do Estado do Brasil, depois de impressa. Comenta Borba: “O Padre Vasconcellos passou apertado, mas também, quem mandou ele dizer que isso que estamos vendo por aqui é o paraíso terrestre?"

Conceitua o autor o que para ele é Coleção Brasiliana: “Todos os livros sobre o Brasil impressos desde o século XVI até fins do século XIX, e os livros de autores brasileiros impressos no estrangeiro até 1808"; e Coleção Brasiliense: "Livros impressos no Brasil, de 1808 até nossos dias". Embora dizendo que "as misturas em coleções, seja lá do que for, não são geralmente de bom gosto" e que "mistura só tem bom gosto em coquetel", sua posição nada radical o leva a acrescentar: "Mas se um bibliófilo quiser colecionar a torto e a direito Brasiliana e Brasiliense, e formar um verdadeiro coquetel de livros, meu Deus, deixem-no juntar seus livrinhos em paz!” 
Já lá para o fim, ao registrar a constante publicação, entre nós, desde as primeiras décadas do século XIX, de romances populares - O Amor Ofendido e Vingado, O Castigo da Prostituição, As Duas Desafortunadas - e romances de cavalaria - História Verdadeira da Princesa Magalona -, relembra Borba: "Até há poucos anos eram editados no Rio constantemente. Havia até a superstição entre editores de que a casa que não editasse um deles não iria adiante. Monteiro Lobato contou-me uma vez que muita gente atribuía sua falência a não ter editado a Princesa Magalona ou a Donzela Teodora ou Os Doze Pares de França”.

Para Lobato, tem ele ainda palavras de grande respeito: "Monteiro Lobato não encontrou tipografia capaz de produzir livros nas quantidades que necessitava. Teve de montar uma oficina, meter-se num negócio estranho e nocivo à sua atividade de editor. Foi à falência. Mas esse grande pioneiro, um dos maiores homens que o Brasil teve e que, se não fosse paulista, seria tão celebrado quanto Rui Barbosa, abriu o caminho".

Antes disso, tecendo considerações sobre a produção da Imprensa Régia, escreve Borba: “Tenho até a impressão de que os poetas da Imprensa Régia mereceriam um estudo literário em conjunto. Talvez então o nosso Antônio José Vaz, que desconfio ser o primeiro poeta paulista a aparecer em letra de fôrma, passasse a ser citado na literatura brasileira". Todavia, logo se corrige em nota de rodapé: “Depois de escrever essas linhas espontaneamente, fiquei desconfiado e fui ler um Cântico do vate paulista, impresso em 1810, a primeira obra que publicou. Confesso que perdi a esperança. O meu palpite foi puro bairrismo. Antônio José Vaz é paulista de trezentos anos, mas um péssimo poeta, não tem a menor chance de ser citado numa história da literatura”.

Não dê a ligeireza das citações, pinçadas à releitura de $O$ Bibliófilo Aprendiz e aqui reproduzidas, a falsa impressão de que Rubens Borba de Moraes seja epidérmico nos assuntos abordados. Ele é da maior consistência, rigor, precisão e de imensa carga informativa ao longo de suas 264 páginas da brochura; mas, mesmo nos capítulos mais carregados do que chamaríamos de detalhes técnicos ou de minúcias bibliográficas, a leitura flui sem despertar cansaço nem aborrecimento.

Termino com a despedida de Borba de Moraes ao cabo de seu livro: "Falta ainda muita coisa que eu gostaria de lhe dizer. Mas, prosa sobre livros não tem fim. Você já deve estar cansado. Quer fechar o livro e ir cuidar da vida. Se cuidar da vida é, para você, ganhar mais dinheiro, digo-lhe que não vale a pena. Ganhar muito dinheiro dá enfarte... Não vive verdadeiramente quem não gosta de dar uma prosa com um amigo ou ler um livro com vagar... Quando nos encontrarmos de novo, espero que seja você quem me conte coisas sobre livros...” 


\section{SIMPLICIDADE ALEGRE DE UM BIBLIÓFILO $p .276$}

RESUMo Este artigo traz uma

apresentação do livro O Bibliófilo

Aprendiz, por ocasião do lançamento

de sua quinta edição brasileira.

O livro foi escrito por Rubens Borba

de Moraes, bibliófilo que decidiu

compartilhar as particularidades de

sua forma de lazer, o colecionismo

de livros.

BIBLIOFILIA • COLECIONISMO •

RUBENS BORBA DE MORAES

- LIVROS.

\section{AMUSING CHAT OF A FINE BIBLIOPHILE}

ABSTRACT This article presents a review of the book O Bibliófilo Aprendiz

(The Bibliophile Apprentice, in a free translation), on the occasion of the release of its fifth Brazilian edition. The book was written by Rubens Borba de Moraes, a bibliophile who decided to share the particularities of his form of leisure, book collecting.

BIBLIOPHILIA • COLLECTING •

RUBENS BORBA DE MORAES

- BOOKS. 